\title{
Angiocentric glioma from a perspective of A-B-C classification of epilepsy associated tumors
}

\author{
Dariusz Adamek ${ }^{1}$, Grzegorz Przemystaw Siwek ${ }^{2}$, Adrian Andrzej Chrobak², Izabela Herman-Sucharska ${ }^{3}$, \\ Stanisław Kwiatkowski ${ }^{4}$, Rafał Morga ${ }^{5}$, Edyta Radwańska ${ }^{1}$, Barbara Urbanowicz ${ }^{6}$ \\ ${ }^{1}$ Department of Neuropathology, Medical College, Jagiellonian University Krakow, ${ }^{2}$ Students' Pathology Scientific Group, \\ Medical College, Jagiellonian University, Krakow, ${ }^{3}$ Department of Electroradiology, Medical College, Jagiellonian University, Krakow, \\ ${ }^{4}$ Department of Pediatric Neurosurgery, University Children's Hospital of Krakow, Medical College, Jagiellonian University, Krakow, \\ ${ }^{5}$ Department of Neurosurgery, University Hospital, Medical College, Jagiellonian University, Krakow, ${ }^{6}$ Electron Microscopy Laboratory, \\ University Children's Hospital of Kraków, Medical College, Jagiellonian University, Krakow, Poland
}

\begin{abstract}
Angiocentric glioma (AG) is a newly-classified, very rare, WHO grade I central nervous system (CNS) lesion, occurring usually in children and young adults. Only 52 patients with AG have been reported so far, making it one of the rarest neuropathological entities. Hereby we present two new cases of AG in young subjects with detailed neuropathological investigations and a neuroradiological picture along with a brief summary of all already published literature reports of this tumor.

Histopathological examination of the resected tissue from both cases revealed similar changes characteristic of AG. The tumors were composed of spindle-like, elongated cells, forming characteristic pseudorosettes around vessels and diffusively infiltrating surrounding tissue, trapping neurons between tumor cells. Noticeably, some neoplastic cells encrusting vessels extended far beyond the main tumor mass. Hypothetically, this may be responsible for the recurrence of the tumor even in the case of apparently total excision. In immunohistochemistry, AG cells were glial fibrillary acidic protein (GFAP) and vimentin positive, also exhibiting a strikingly significant epithelial membrane antigen (EMA) dot-like staining pattern. In one of the cases, electron microscopy revealed ependymal differentiation features such as microvilli and cilia. Taken together, all these data strongly confirm a dual astroglial-ependymal nature of the tumor. Follow up corroborates benign character of this neoplasm. Both AGs reported here were immunonegative for the product of the mutated IDH-1 gene what, according to our best knowledge, has never been reported so far. It may suggest that in their pathogenesis AGs differ from grade II astrocytomas, which in most cases harbor a mutation of IDH-1. Noteworthy, neuroimaging in our cases was relatively characteristic but not conclusive, therefore biopsy (at least) is mandatory. A newly proposed so called "A-B-C" classification of long-term epilepsy-associated tumors (LEATS) places AG in a category named ANET. The authors shortly review the A-B-C classification of LEATS.
\end{abstract}

Key words: angiocentric, glioma, electron microscopy, drug-resistant epilepsy, seizures, immunohistochemistry, LEATs, epileptomas. 


\section{Introduction}

Angiocentric glioma ( $\mathrm{AG}$ ) is a very rare low-grade neoplasm, mainly affecting children and young adults. So far, to our best knowledge only 52 cases have been reported, with first literature reports dating back to 2005, when two different cases of central nervous system (CNS) lesions were described as a new pathological entity, due to their specific magnetic resonance imaging (MRI) appearance and glial and ependymal differentiation in histopathological examination [11,29]. Those findings were included in the 2007 World Health Organization (WHO) Classification of Tumours of the Central Nervous System, which classified AG as WHO I grade tumor [14]. Angiocentric glioma occurs in a broad age range, varying from 2 to 70 years of age, however it seems to affect more frequently children and young adults. Angiocentric glioma grows predominantly in supratentorial locations, usually in frontal and temporal cortex, however there are cases of lesions localized in mid-brain, amygdalae and hippocampus [13,17,19,23]. A typical symptom of AG is drug-resistant epilepsy. Some patients suffer also from headaches and vision impairments. In MRI examination, AG forms a well-demarcated lesion, hyperintense on T2 and hypointense on T1-weighted image, with "stalk-like" protrusions towards ventricle [11]. Calcifications are only rarely observed [24]. Most common treatment is surgical resection, which seems to be the most beneficial for the patients. In histopathological examination, tumor tissue exhibits a very characteristic growth pattern, in its most typical form composed of elongated, spindle like cells, arranged radially and longitudinally around vessels and forming palisade-like structures under pia. Angiocentric glioma cells exhibit a low proliferative rate, with reported labeling Ki-67 (MIB-1) indices ranging from 1 to $5 \%$, what corroborates with benign clinical behavior observed in these tumors [12]. Notwithstanding some cases with higher mitotic rates were also reported [12,22]. In AG one can observe traits of both astroglial and ependymal-originated cells, what may suggest an origin from a hypothetical common progenitor cell. Angiocentric glioma proves to be a challenge, as the main symptom i.e. drug-resistant epilepsy and its complications e.g. cranial trauma can be misleading in the diagnostic process. Predilection to frontal and temporal cortex is also troublesome, therefore surgical resections need to be performed with extra caution, best - using neuronavigation methods, with the help of $f M R I$ and diffusion tensor imaging (fibertracking). Due to relatively scarce information about the clinical course, optimal methods of treatment, and prognosis, every piece of information is valuable to establish valid, evidence-based methods of handling this condition. In this study, we present 2 cases of young patients with $\mathrm{AG}$ and a thorough functional and radiological examination, performed before the surgery.

\section{Material and methods \\ Case 1}

A girl aged 11 years was admitted to the regional hospital after an episode of generalized seizures. Electroencephalography (EEG) and MRI were performed. Electroencephalography examination revealed an abnormal pattern with numerous seizure spikes, registered bilaterally over frontal lobes, with the predominance of the left frontal lobe and the tendency of generalization. Magnetic resonance imaging revealed a T1 hypointense, T2 hyperintense lesion located in the left frontal lobe (Fig. 1A-E), sized $25 \times 35 \times 45 \mathrm{~mm}$. The patient was transferred to the University Children's Hospital in Krakow with a diagnosis of brain tumor. Due to the vital site of the change (proximity to left motor and sensory cortex), additional methods of imaging: fMRI and tractography were performed to minimize the risk of collateral damage. Gross total resection of the tumor was achieved, the patient was released home with no signs of focal brain injury. During 16 months' post-operative period, neither further seizures nor other symptoms of tumor recurrence were noted.

\section{Case 2}

A male aged 25 years with no previous history of any health problems was admitted to the hospital after 3 episodes of seizures. As a result of the last epileptic episode, the patient suffered from facial trauma. In neurological examination, no signs of focal brain injury have been found. Computed tomography (CT) revealed a hyperdensive, well-demarcated mass, size of $21 \times 8 \mathrm{~mm}$, located in the left frontal lobe. The mass was surrounded by a zone of grade I edema. The ventricular system of the brain showed no pathological changes. Initially, the lesion was interpreted as a hemorrhagic focus of brain concussion. Due to the unknown origin of the two initial 

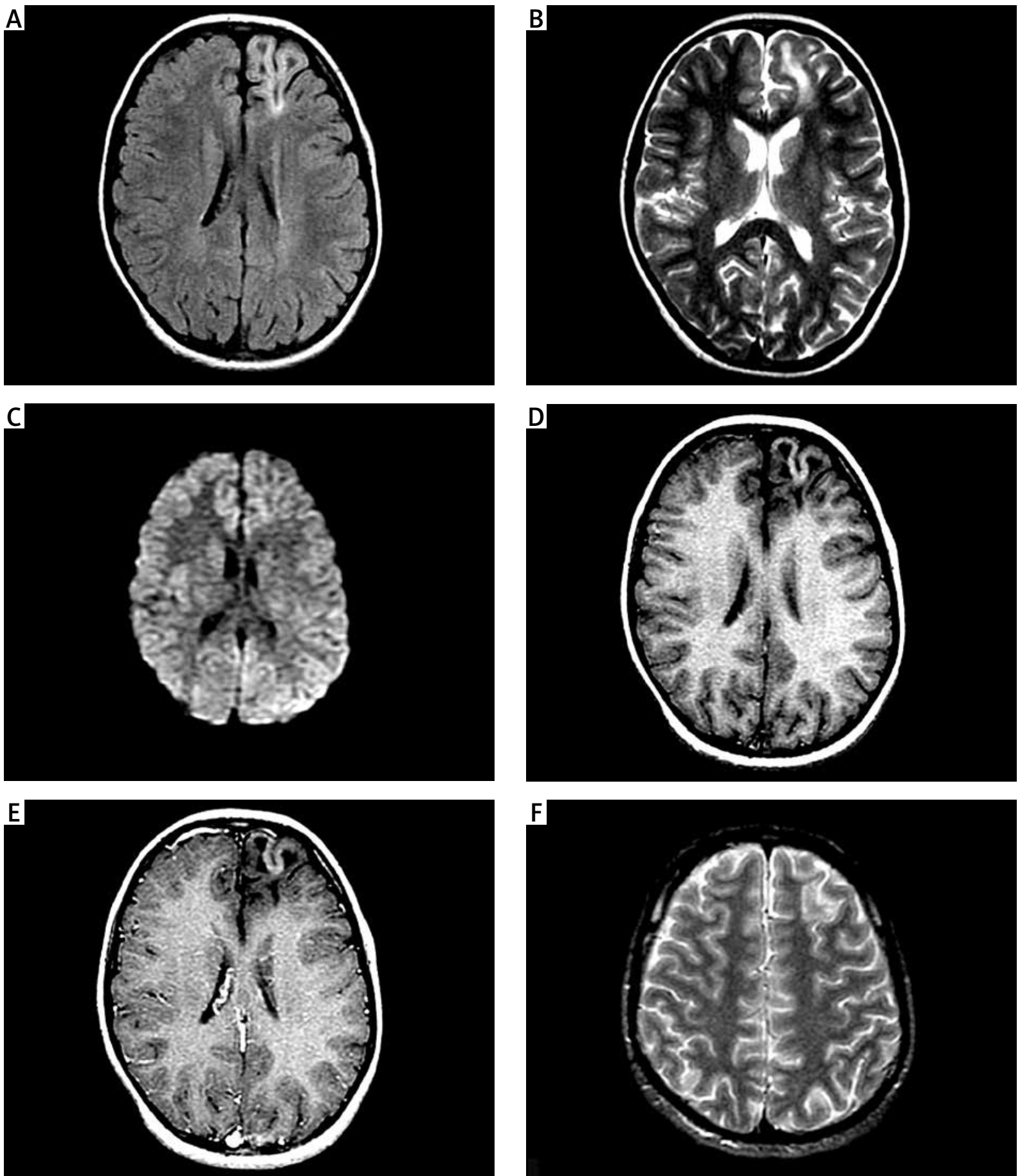

Fig. 1. Magnetic resonance imaging. Case No 1. A) Partially hyperintense cortically based lesion in the left frontal lobe. MRI; axial plain; FLAIR sequence. B) Hyperintense lesion with stalk-like extension toward the ventricle. MRI; axial plain; frFSET2 sequence. C) No evidence of restriction diffusion inside the lesion. MRI; axial plain; DWI sequence. D) Ribbon-like hyperintense rim. MRI; axial plain; SET1 sequence. E) No enhancement inside the tumor. MRI; axial plain; postcontrast SET1. F) Case No 2. Slightly bubbly hyperintense lesion in the frontal lobe, without evidence of expansion. MRI; axial plain; frFSET2. 
seizures, the patient was qualified for MRI, which showed T2 hyperintense, T1 hypointense mass, located in the left frontal lobe, forming a cone-like structure (Fig. 1F), sized about $25 \times 15 \times 30 \mathrm{~mm}$ ranging from the pia up to $5 \mathrm{~mm}$ distance from the left lateral ventricle. The patient showed no neurological or neuropsychological abnormality. Left frontal craniotomy revealed a widened brain lobule, containing the whole mass of the tumor. The lesion was dissected with the help of neuronavigation based on brain MRI. Neurological status of the patient after the surgery did not deteriorate. On the seventh day after the surgery one episode of seizures was noted. During 40 months' follow-up repeated MRI and EEG excluded the recurrence of the tumor. Also no further seizures were observed.

\section{Results}

In both presented cases, histopathological and immunohistochemical examination of the resected tissue revealed an identical pattern (summary of immunohistochemical methods applied given in Table I). The tumors were composed of elongated cells (Fig. 2A), characteristically surrounding vessels and forming pseudorosette structures around them (Fig. 2B, C). A few delicate perivascular accumulations of glioma cells extended to some distance out of the main tumor mass (Fig. 2D). Tumor cells, adjacent to pia created a conspicuous palisading pattern (Fig. 2A). Inside of the tumor tissue, there were remaining Neu- $\mathrm{N}$ positive neurons, some of them trapped between AG cells, which all were immunonegative for Neu-N (Fig. 2E). Tumor cells were negative for synaptophysin, what contrasted with synaptophysin-positive neuropil background (Fig. 2F). Glioma cells were strongly immunopositive for GFAP, what indicates their astrocytic differentiation (Fig. 2G), noticeably showing conspicuous dot-like positivity for EMA, which is regarded as a signature of ependymoma (Fig. 2H). Ependymal traits were further confirmed by electron microscopy, which showed numerous microvilli, tight junctions and cilia (Fig. 21) (electron microscopy was performed only in Case 1). In both cases tumor cells were strongly positive for vimentin and totally negative for cytokeratins (AE1/ AE3). Moreover, both cases were immunohistochemically negative for mutated product of the isocitrate dehydrogenase (IDH-1) gene. Mitoses were absent and only exceptionally, single Ki-67 immunopositive nuclei were seen. Taken together, in both cases the morphological features and the pattern of immunoexpression were pathognomonic for AG.

\section{Discussion}

Considering many factors such as age, gender, localization and symptomatology of the disease, both cases present a typical course of AG. In the published cases (summarized in Table II), mean age of diagnosis was almost 18 years (mean $=17.7$, $\mathrm{SD}=16$ ). So far, AG has been presented in 23 female and 29 male patients (total number: 52). Reported cases were located in temporal lobes (20 cases,

Table I. Summary of immunohistochemistry

\begin{tabular}{|c|c|c|c|c|c|}
\hline Name & Company & Dillution & Unmasking & Incubation time & Detection \\
\hline GFAP & DAKO & $1 / 50$ & EDTA & $30 \min$ & EnVision \\
\hline EMA & DAKO & $1 / 100$ & - & $30 \mathrm{~min}$ & EnVision \\
\hline CD34 & DAKO & $1 / 50$ & Citrate buffer & $60 \min$ & EnVision \\
\hline S-100 & DAKO & $1 / 400$ & - & $30 \min$ & EnVision \\
\hline Vim & DAKO & Ready to use & - & $30 \mathrm{~min}$ & EnVision \\
\hline AE1/AE3 & DAKO & $1 / 50$ & Proteinase & $30 \mathrm{~min}$ & EnVision \\
\hline Ki-67 & DAKO & 25-Jan & EDTA & $24 \mathrm{~h}$ & EnVision \\
\hline Neu-N & Millipore & $1 / 100$ & Citrate buffer & $24 \mathrm{~h}$ & $\begin{array}{c}\text { UltraVision HRP } \\
\text { Polymer }\end{array}$ \\
\hline Synaptophysine & DAKO & 20-Jan & EDTA & $30 \mathrm{~min}$ & Envision \\
\hline $\mathrm{IDH}-1$ & Dianova & $1 / 100$ & Citrate buffer & $30 \mathrm{~min}$ & $\begin{array}{c}\text { UltraVision HRP } \\
\text { Polymer }\end{array}$ \\
\hline
\end{tabular}


A
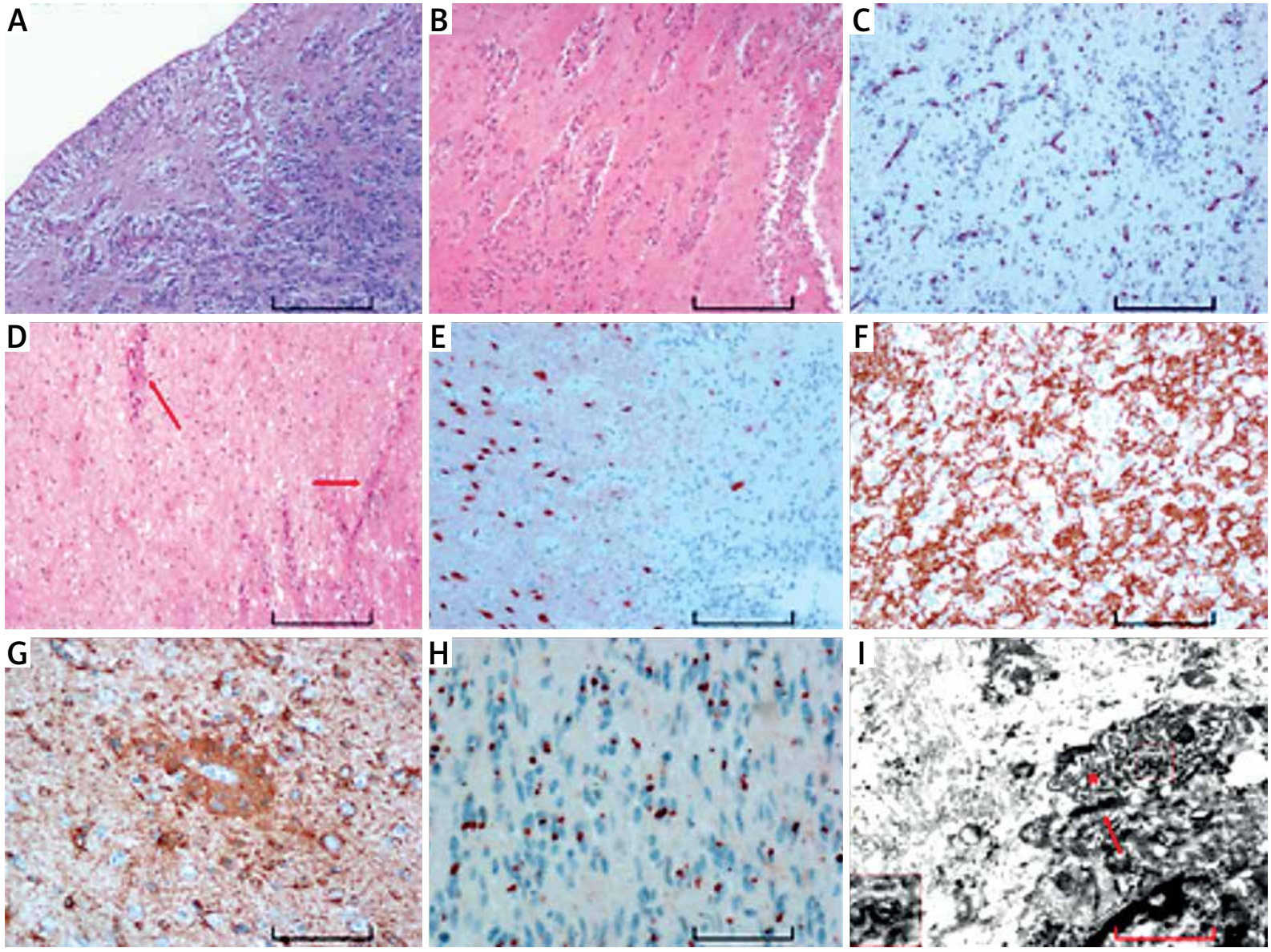

Fig. 2. Angiocentric glioma. Tumor outgrowth within the cortex, reaches pia, where it forms a palisade-like pattern (A) and characteristic pseudorosettes around vessels (B). Perivascular arrangement is well observed in a slide stained immunohistochemically for CD34 - marker of endothelial cells (C). Some vessels encrusted with single bona fide glioma cells (D, see arrows) extend relatively far away from the main tumor mass (D). Within the invaded cortex, there are still numerous remaining neurons (E). Synaptophysin-negative tumor cells contrast strongly with positive neuropil background (F). Cells show strong immunopositivity for GFAP (G) and dot-like immunopositivity for EMA (H). Electron microscopy revealed numerous microvilli (i, asterisk), cilia (i, marked with a quadrangle and enlarged in the inset), and tight junctions (i, arrowhead). Methods applied: A, B, D - hematoxylin-eosin, C - CD34, E - Neu-N, F - synaptophysin, G - GFAP, H - EMA immunostaining, I- electron microscopy. Case 1 represented in: A, C, E, F, G, I, case 2 represented in: B, D, H.

out of which 6 in hippocampus and 6 in amygdala), frontal lobes (18), parietal lobes (13), occipital lobes (5), insula (2) brainstem (1), thalamus (1) (the numbers do not add up to a total of 52 , since in some reports locations overlap more than 1 lobe). 40/52 patients presented seizures which can be regarded as the most typical symptom of this tumor. Only a few patients suffered from focal neurological symptoms. Accordingly, in both presented cases the most prominent symptoms were also seizures, resistant to typical anti-epileptic treatment. In case $1 \mathrm{MRI}$ has shown a well-demarcated lesion, with no signs of the mass effect (Fig. 1A-E). In case 2 the correct diagnosis was hindered by radiological signs of brain contusion, caused by trauma in the course of epileptic seizures. Consecutively MRI imaging revealed a lesion, suggestive of a benign/ low-malignant tumor (Fig. 1F). According to WHO 2007 Classification of Tumours of the Central Nervous System, major differential diagnosis in the case of a well-delineated cortically based lesion in the frontal lobe in children with epilepsy is angiocentric glioma, oligodendroglioma, dysembryoplastic neuroepithelial tumor (DNT) and ganglioglioma[21]. Dysembryoplastic 
Table II. Summary of the reported cases of AG

\begin{tabular}{|c|c|c|c|c|c|}
\hline Authors & Year & $\begin{array}{c}\text { Age of } \\
\text { diagnosis }\end{array}$ & Gender & Localisation & Symptoms \\
\hline Alexandru et al. & 2013 & 12 & $\mathrm{~F}$ & Left frontotemporal & Seizures \\
\hline Lu et al. & 2013 & 15 & M & Right frontal & $\begin{array}{c}\text { Progressive left-sided weakness } \\
+ \text { headache }\end{array}$ \\
\hline Aguilar et al. & 2012 & 15 & M & Right anterior frontal & $\begin{array}{l}\text { Progressive left-sided weakness } \\
+ \text { umbness }\end{array}$ \\
\hline \multirow[t]{3}{*}{ Liu et al. } & \multirow[t]{3}{*}{2012} & 14 & M & $\begin{array}{l}\text { Right posterior inferior } \\
\text { temporal }\end{array}$ & Seizures \\
\hline & & 22 & M & $\begin{array}{l}\text { Left temporal + amygdala + } \\
\text { hippocampus }\end{array}$ & Seizures \\
\hline & & 13 & $\mathrm{~F}$ & Anterior temporal + amygdala & Seizures \\
\hline Koral et al. & 2012 & 4 & M & Right temporal & Development and speech delay \\
\hline \multirow[t]{2}{*}{ Grajkowska et al. } & \multirow[t]{2}{*}{2011} & 15 & $\mathrm{~F}$ & Right temporal & Seizures \\
\hline & & 14 & M & Left occipito-parietal & Seizures \\
\hline Miyahara et al. & 2011 & 66 & $\mathrm{~F}$ & Right insula & Seizures \\
\hline Takada et al. & 2011 & 26 & M & Right superior frontal & Seizures \\
\hline \multirow[t]{2}{*}{ Miyata et al. } & \multirow[t]{2}{*}{2012} & 54 & $\mathrm{~F}$ & Left hippocampus + amygdala & Seizures \\
\hline & & 37 & $M$ & Left uncus + amygdala & Seizures \\
\hline Rho et al. & 2011 & 10 & $\mathrm{~F}$ & Right medial frontal & Dizziness, otalgia, nystagmus \\
\hline \multirow[t]{5}{*}{ Marburger et al. } & \multirow[t]{5}{*}{2011} & 10 & $\mathrm{~F}$ & Left parieto-occipital & Seizures \\
\hline & & 15 & M & $\begin{array}{l}\text { Left temporal + amygdala + } \\
\text { hippocampus }\end{array}$ & Seizures \\
\hline & & 19 & M & Left parietal & Seizures \\
\hline & & 3 & $\mathrm{~F}$ & $\begin{array}{c}\text { Left temporal + amygdala + } \\
\text { hippocampus }\end{array}$ & Seizures \\
\hline & & 15 & M & Right thalamus & Headache + visual disturbances \\
\hline Pokharel et al. & 2011 & 3 & M & Right posterior parietal & Seizures \\
\hline Hu et al. & 2010 & 19 & M & Left frontal & Dizziness \\
\hline Mott et al. & 2010 & 57 & $\mathrm{~F}$ & Right frontal & $\begin{array}{c}\text { Seizures, left hand tremor, } \\
\text { headaches }\end{array}$ \\
\hline \multirow[t]{3}{*}{ Shakur et al. } & \multirow[t]{3}{*}{2009} & 13 & $\mathrm{~F}$ & Left anterior temporal & Seizures + headaches \\
\hline & & 10 & M & Left posterior temporal & $\begin{array}{l}\text { Hearing impairment, shortening } \\
\text { attention span }\end{array}$ \\
\hline & & 10 & M & Left middle temporal & Seizures \\
\hline Covington et al. & 2009 & 5 & $\mathrm{~F}$ & Exophytic on brainstem & $\begin{array}{l}\text { Severe cranial neuropathy + gait } \\
\text { disturbance }\end{array}$ \\
\hline Fulton et al. & 2009 & 2 & M & Right frontoparietal & Seizures \\
\hline Lum et al. & 2008 & 5 & $M$ & Right frontal & Seizures \\
\hline Sugita et al. & 2008 & 6 & $M$ & Right occipitoparietal & Seizures \\
\hline
\end{tabular}


Table II. Cont.

\begin{tabular}{|c|c|c|c|c|c|}
\hline Authors & Year & $\begin{array}{c}\text { Age of } \\
\text { diagnosis }\end{array}$ & Gender & Localisation & Symptoms \\
\hline \multirow[t]{8}{*}{ Preusser et al. } & \multirow[t]{8}{*}{2007} & 15 & M & Precuneus & Seizures \\
\hline & & 6 & M & Medial temporal & Seizures \\
\hline & & 17 & M & Frontoparietal & Psychomotor disturbance \\
\hline & & 9 & $\mathrm{~F}$ & Medial inferior temporal & Psychomotor disturbance \\
\hline & & 37 & $\mathrm{~F}$ & Hippocampus & Seizures \\
\hline & & 70 & $\mathrm{~F}$ & Hippocampus & Psychomotor disturbance \\
\hline & & 35 & M & Parietal & Psychomotor disturbance \\
\hline & & 15 & F & Precuneus & Seizures \\
\hline \multirow[t]{8}{*}{ Wang et al. } & \multirow[t]{8}{*}{2005} & 3 & M & Left occipital & Seizures \\
\hline & & 14 & M & Right inferior frontal & Seizures \\
\hline & & 3 & $\mathrm{~F}$ & Left occipital & Seizures \\
\hline & & 4 & $\mathrm{~F}$ & Right parietal & Seizures \\
\hline & & 30 & $\mathrm{~F}$ & Left anterior temporal & Seizures \\
\hline & & 26 & M & Left frontal & Seizures \\
\hline & & 37 & M & Right frontal & Seizures \\
\hline & & 15 & $\mathrm{~F}$ & Right medial temporal & Seizures \\
\hline \multirow[t]{7}{*}{ Lellouch-Tubiana et al. } & \multirow[t]{7}{*}{2005} & 2 & M & Right frontoparietal & Seizures \\
\hline & & 4.5 & M & Right parietal & Seizures \\
\hline & & 6.5 & M & Left frontoparietal & Seizures \\
\hline & & 3 & $\mathrm{~F}$ & Left frontal & Seizures \\
\hline & & 4 & $\mathrm{~F}$ & Left medial temporal & Seizures \\
\hline & & 9.5 & $\mathrm{~F}$ & Left frontal & Seizures \\
\hline & & 13 & $\mathrm{~F}$ & $\begin{array}{l}\text { Right orbitofrontal, gyrus } \\
\text { rectus, insula }\end{array}$ & Seizures \\
\hline
\end{tabular}

neuroepithelial tumor has more "bubbly" appearance on T2w images. Oligodendroglioma is a gray-white matter interface originated mass. Angiocentric glioma typically expands gyri, creates $\mathrm{T} 1 \mathrm{w}$ hyperintense rim and stalk-like extension toward the ventricle [11]. The clue in proper diagnosis of this tumor may also be intrinsic ribbon-like T1 shortening [10]. Gangliogliomas often enhance, while angiocentric gliomas do not. The most typical findings of angiocentric glioma are presented in Case 1.

In Case 1 the operation was performed with the help of the neuronavigation, thus reducing the risk of complications. In this case, during so far 16 months' follow-up, no epileptic seizures have been observed, what is consistent with a typical course of the disease, according to the literature. In case 2, only one episode of the seizures was observed soon after surgery, but there were no seizures in the follow-up (42 months). One may speculate that this single episode of seizures reflected rather a side effect of post-operation damage, than the result of residual tumor tissue. Neuropathological investigation of resected tumors have shown a common characteristic picture of AG with especially conspicuous perivascular crowding of cells, subpial palisading, and a typical immunohistochemical staining pattern indicating shared astrocytic and ependymal properties of tumor cells. 
In histopathological differential diagnosis of this tumor one needs to include low-grade neoplasms, such as DNT, which also occurs in children and manifests clinically by seizures. Literature theoretically indicates focal cortical dysplasia, low-grade astrocytoma [22], ependymoma, astroblastoma and papillary glioneuronal tumor, and even also subependymoma, pilocytic astrocytoma, and ganglion cell tumor as candidates for differential diagnosis [3]. The presence of tumor cells in distant regions from the original mass should be also noted, as it might contribute to the observed tendency for recurrence of this tumor. Neurosurgeons might contribute to these data, while planning secondary resection of the recurring tumor by further enlarging the operation area in proximity of the vessels.

In practice the most important options of differential diagnosis encompass astroblastoma, ependymoma and (less importantly) papillary glioneuronal tumor.

Given the twofold nature of AG (features of both glial and ependymal cells), it is plausible that the tumor itself could originate from the early progenitor cell. There are scarce data concerning pathophysiology of this tumor. In electron microscopy AGs exhibit signs of ependymal differentiation (microvilli, cilia, tight junctions) [29]. A diffuse infiltration pattern along with presence of immunopositivity for S100, GFAP, and vimentin is consistent with the glial (especially astrocytic) character of the tumor. Immunonegativity for synaptophysin and Neu-N helps to exclude the papillary glioneuronal tumor. The differentiation of AG with astroblastoma and ependymoma is more troublesome. Ependymoma (apart from the different location in most cases) microscopically seems to present with more slender cell nuclei and less distinct cell boundaries, and reactivity for GFAP also seems to be less pronounced than in AG. Even more disputable is to set guidelines for differentiation between AG and astroblastoma, since among others, an electromicroscopic picture may be similar to that of AG. Probably, the most helpful clue, speaking in favor of astroblastoma is the lack of subpial palisading and presence of vascular sclerosis and hyalinization [3]. Regarding its cellular composition AG, in contrast to diffuse astrocytoma, is much more monomorphic [16]. In most cases of AG, a low mitotic count is observed. However, if a high mitotic count is present it does not alter the benign character of growth [22].

According to new proposals of Blumcke et al., angiocentric gliomas make a separate entity (so called angiocentric neuroepithelial tumor - ANET), included in the group of tumors characteristically related to epilepsy and hence accordingly named "long-term epilepsy associated tumors" (LEATs). "Long-term epilepsy associated tumors" incorporate a large variety of neuronal and glial tumors that are encountered in patients, surgically treated for a long-time epilepsy (over 2 years). Typically, LEATs are benign tumors with presence of the neuronal component and predilection to neocortical regions, especially temporal lobes. They tend to acquire their epileptogenic potential in young age, thus in most cases, first symptoms of these neoplasms are focal seizures. "Long-term epilepsy associated tumors" present slow growth rates, therefore the prognosis for the patients, even without the radical surgery, are generally very good. However in a number of cases, progression of seizures or even anaplastic transformation to higher WHO grades have been observed [28]. Blumcke et al. proposed a new approach to diagnosing and treatment of a group of these tumors. This approach is applicable for both clinicians (that are responsible for weighing the risk and gains from surgery) and neuropathologists. While in the case of adult and elderly patients, diagnosis of a brain tumor is usually followed by the resection of the lesion, in LEATs patients this might not be the only conceivable way of proceeding. Children and young adults with the lesions located in typical locations for LEATs (e.g. temporal lobes) could be managed differently. At first, careful examination with the help of experienced neuroradiologists is mandatory. Due to a slow growth rate and benign behavior of the tumor, pharmacological treatment is to be introduced to achieve seizure control, however bearing in mind the adverse long-term effects of medication and impact of uncontrolled seizures on patients' cognition. When this option turns to be ineffective, surgical resection is advocated. During the surgery, one has to bear in mind that some types of LEATs tend to infiltrate the radiologically-unchanged tissue, therefore in a non-dominant lobe, gross resection of the tumor including adjacent tissues is advised. If the tumor is localized in the dominant lobe or in close proximity to vital brain regions, invasive electrocorticography is strongly advised to limit the damage, while allowing to achieve the best available effect. Regarding pathological examination of the lesion, Blumcke et al. proposed a new A-B-C classification of epilepsy-associated tumors, that is focused on immunochem- 
istry markers (MAP2, CD34). In the case of AG, the authors proposed returning to the original term of "angiocentric neuroepithelial tumor" (ANET) [11]. Other items of A-B-C nomenclature include: BNET, CNET, DNET, ENET, GNET, INET. BNETs, regarded as "basic" oncofetal neuroepithelial tumors, are positive for CD34, and as for now are typically diagnosed as gangliogliomas. In contrast, CD34-negative tumors so far also typically diagnosed as gangliogliomas are named GNETs ("gangliocytic" neuroepithelial tumors). CNET and DNET refer to a complex (CNET), and simple ("typical") respectively form of dysembryoplastic neuroepithelial tumor $($ DNET $=$ DNT). ENET, in turn, is a sort of an imprecisely defined category for tumors, negative for CD34 (ENET standing for "epileptogenic NET not otherwise specified"). Lastly, INET is to be referred to tumors so far termed as "isomorphic astrocytomas" - a variant of diffuse astrocytoma, characterized by very low cellularity and strikingly uniformed, regular morphology. Supposedly, though being diffused, they deserve rather WHO grade I than II [4].

Our results confirm the proposed diagnostic criteria of ANET (as an equivalent of AG): tumor cells in both samples were CD34 and IDH-1 negative, EMA immuno-staining showed a dot-like pattern as well as palisade-like growth pattern around the vessel. The presence of tumor cells in distant regions from the original mass should be also noted, as it might contribute to the observed tendency for recurrence of this tumor. Neurosurgeons might contribute to these data, while planning secondary resection of the recurring tumor by further enlarging the operation area in proximity of the vessels.

There are attempts to characterize the genetic signature of AGs, Preusser et al. using comparative genetic hybridization did not find any specific gene marker for AG: genetic aberrations in tumor cells were sparse and heterogeneous, however in 1 out of 8 cases a severe genetic imbalance was found. This aberration was a loss of chromosomal bands 6q24-q25. Imbalance on $6 \mathrm{q}$ is observed in many neoplasms, more interestingly, it has been described as frequent in intracranial ependymomas. Preusser states that a potential candidate gene located on 6q24.1 is PLAGL1/ZAC1 gene, which is an important transcription factor receptor, involved in regulation of the cell cycle and apoptosis. Even more interesting is that the features of neuronal degenerations (neurofibrillary tangles and A $\beta$ plaques) in "trapped neurons" were found [23]. Vast majority of the cases presented a benign course of the disease - some patients with a history of the seizures counted in decades $[20,23]$. Despite that, supposedly malignant variants of AG (possibly WHO III), characterized by a higher mitotic index, vascular proliferation and necroses were also observed $[1,15]$. The elective method of treatment is gross total resection, but subtotal resection and chemotherapy and radiotherapy had also been used, especially in more difficult locations or to handle rare, high grade variants $[1,5,16,20]$. One has to acknowledge that the neuroradiological picture, though characteristic, is not definitely specific therefore at least biopsy is mandatory. The aforementioned presence of tumor cells well beyond the main tumor mass speaks in favor of the necessity of gross total resection (if possible). This approach not only should lower the risk of recurrence, but also might be of importance in treatment of epilepsy. Prognosis after gross total resection is very good, with a low incidence of recurrence of the seizures in long-term follow up and only 2 registered cases of death in the post-operative period [22]. According to Pokharel et al., thanks to the benign character of AG (confirmed by biopsy), some patients may live without the need of gross removal of tumor (radiotherapy only), what can be vital, especially for elderly patients [22]. New technologies like MRI, MRI-spectroscopy, diffusion tensor MRI have enabled neurosurgeons to limit collateral damage and precisely remove even diffusely infiltrating AG masses thus eliminating the origin of epileptic seizures. Our observations indicate that the vessels surrounded by tumor cells extend relatively far away from the main tumor mass (Fig. 2D), and that implies the risk of regrowth even if such event happens relatively long after surgery. We have found both AGs reported here to be immunonegative for the product of the mutated IDH-1 gene, which according to our best knowledge has never been reported so far. We are aware that it does not necessarily indicate a universal characteristic of AG, however at least in the reported cases IDH-1 negativity provides evidence that in their pathogenesis AGs differ from grade II astrocytomas, which in most cases harbor a mutation of IDH-1 [9].

\section{Acknowledgments}

The paper has been supported by Jagiellonian University in Kraków grant: No. KZDS/003862 and partially by Dariusz Adamek Specjalistyczna Prak- 
tyka Lekarska Patomorfologia - Neuropatologia, ul. Zachodnia 8/3 30-350 Kraków NIP 6571874155.

\section{Disclosure}

\section{Authors report no conflict of interest.}

\section{References}

1. Aguilar HN, Hung RW, Mehta V, Kotylak T. Imaging characteristics of an unusual, high-grade angiocentric glioma: a case report and review of the literature. J Radiol Case Rep 2012; 6: 1-10.

2. Alexandru D, Haghighi B, Muhonen MG. The treatment of angiocentric glioma: case report and literature review. Perm J 2013; 17: e100-2.

3. Burger PC, Scheithauer BW, Kleinschmidt-DeMasters BK, Ersen A Rodriguez FJ, Tihan T, Rushing EJ. Diagnostic Pathology - Neuropathology. 1st ed. AMIRSYS Inc., Salt Lake City 2012, pp. 126-131.

4. Blumcke I, Aronica E, Urbach H, Alexopoulos A, Gonzalez-Martinez JA. A neuropathology-based approach to epilepsy surgery in brain tumors and proposal for a new terminology use for longterm epilepsy-associated brain tumors. Acta Neuropathol 2014. 128: 39-54

5. Covington DB, Rosenblum MK, Brathwaite CD, Sandberg DI. Angiocentric glioma-like tumor of the midbrain. Pediatr Neurosurg 2009; 45: 429-433.

6. Fulton SP, Clarke DF, Wheless JW, Ellison DW, Ogg R, Boop FA Angiocentric glioma-induced seizures in a 2-year-old child. J Child Neurol 2009; 24: 852-856.

7. Grajkowska W, Matyja E, Daszkiewicz P, Roszkowski M, Peregud Pogorzelski J, Jurkiewicz E. Angiocentric glioma: a rare intractable epilepsy-related tumour in children. Folia Neuropathol 2014; 52: 253-259.

8. Hu XW, Zhang YH, Wang JJ, Jiang XF, Liu JM, Yang PF. Angiocentric glioma with rich blood supply. J Clin Neurosci 2010; 17: 917-918.

9. Ichimura K, Pearson DM, Kocialkowski S, Bäcklund LM, Chan R, Jones DT, Collins VP. IDH1 mutations are present in the majority of common adult gliomas but rare in primary glioblastomas. Neuro Oncol 2009; 11: 341-347.

10. Koral K, Koral KM, Sklar F. Angiocentric glioma in a 4-year-old boy: imaging characteristics and review of the literature. Clin Imaging 2012; 36: 61-64.

11. Lellouch-Tubiana A, Boddaert N, Bourgeois M, Fohlen M, Jouvet A, Delalande O, Seidenwurm D, Brunelle F, Sainte-Rose C. Angiocentricneuroepithelial tumor (ANET): a new epilepsy-related clinicopathological entity with distinctive MRI. Brain Pathol 2005; 15: 281-286.

12. Li JY, Langford LA, Adesina A, Bodhireddy SR, Wang M, Fuller GN. The high mitotic count detected by phospho-histone $\mathrm{H3}$ immunostain does not alter the benign behavior of angiocentric glioma. Brain Tumor Pathol 2012; 29: 68-72.

13. Liu CQ, Zhou J, Qi X, Luan GM. Refractory temporal lobe epilepsy caused by angiocentric glioma complicated with focal cortical dysplasia: a surgical case series. J Neurooncol 2012; 110: 375-380.

14. Louis DN, Ohgaki H, Wiestler OD, Cavenee WK, Burger PC, Jouvet A, Scheithauer BW, Kleihues P. The 2007 WHO classifi- cation of tumours of the central nervous system. Acta Neuropathol 2007; 114: 97-109.

15. Lu JQ, Patel S, Wilson BA, Pugh J, Mehta V. Malignant glioma with angiocentric features. J Neurosurg Pediatr 2013; 11: 350-355.

16. Lum DJ, Halliday W, Watson M, Smith A, Law A. Cortical ependymoma or monomorphousangiocentric glioma? Neuropathology 2008; 28: 81-86.

17. Marburger T, Prayson R. Angiocentric glioma: a clinicopathologic review of 5 tumors with identification of associated cortical dysplasia. Arch Pathol Lab Med 2011; 135: 1037-1041.

18. Miyahara H, Toyoshima $Y$, Natsumeda M, Uzuka T, Aoki H, Nakayama Y, Okamoto K, Fujii Y, Kakita A, Takahashi H. Anaplastic astrocytoma with angiocentric ependymal differentiation. Neuropathology 2011; 31: 292-298.

19. Miyata H, Ryufuku M, Kubota Y, Ochiai T, Niimura K, Hori T. Adult-onset angiocentric glioma of epithelioid cell-predominant type of the mesial temporal lobe suggestive of a rare but distinct clinicopathological subset within a spectrum of angiocentric cortical ependymal tumors. Neuropathology 2012; 32: 479-491.

20. Mott RT, Ellis TL, Geisinger KR. Angiocentric glioma: a case report and review of the literature. Diagn Cytopathol 2010; 38: 452-456.

21. Osborn AG, Salzman KL, Thurnher MM, Rees JH, Castillo M. The new World Health Organization Classification of Central Nervous System Tumors: what can the neuroradiologist really say? AJNR Am J Neuroradiol 2012; 33: 795-802.

22. Pokharel S, Parker JR, Parker JC Jr, Coventry S, Stevenson CB, Moeller KK. Angiocentric glioma with high proliferative index: case report and review of the literature. Ann Clin Lab Sci 2011; 41: 257-261.

23. Preusser M, Hoischen A, Novak K, Czech T, Prayer D, Hainfellner JA, Baumgartner C, Woermann FG, Tuxhorn IE, Pannek HW, Bergmann M, Radlwimmer B, Villagrán R, Weber RG, Hans VH. Angiocentric glioma: report of clinico-pathologic and genetic findings in 8 cases. Am J Surg Pathol 2007; 31: 1709-1718.

24. Rho GJ, Kim H, Kim HI, Ju MJ. A case of angiocentric glioma with unusual clinical and radiological features. J Korean Neurosurg Soc 2011; 49: 367-369.

25. Shakur SF, McGirt MJ, Johnson MW, Burger PC, Ahn E, Carson BS, Jallo Gl. Angiocentric glioma: a case series. J Neurosurg Pediatr 2009; 3: 197-202.

26. Sugita Y, Ono T, Ohshima K, Niino D, Ito M, Toda K, Baba H. Brain surface spindle cell glioma in a patient with medically intractable partial epilepsy: a variant of monomorphousangiocentric glioma? Neuropathology 2008; 28: 516-520.

27. Takada S, Iwasaki M, Suzuki H, Nakasato N, Kumabe T, Tominaga T. Angiocentric glioma and surrounding cortical dysplasia manifesting as intractable frontal lobe epilepsy - case report. Neurol Med Chir (Tokyo) 2011; 51: 522-526.

28. Thom M, Blümcke I, Aronica E. Long-term epilepsy-associated tumors. Brain Pathol 2012; 22: 350-379.

29. Wang M, Tihan T, Rojiani AM, Bodhireddy SR, Prayson RA, lacuone JJ, Alles AJ, Donahue DJ, Hessler RB, Kim JH, Haas M, Rosenblum MK, Burger PC. Monomorphous angiocentric glioma: a distinctive epileptogenic neoplasm with features of infiltrating astrocytoma and ependymoma. J Neuropathol Exp Neurol 2005; 64: 875-881. 